\title{
ANTIGENS FROM PIG CYSTICERCOSIS AND THEIR VALUABILITY IN DIAGNOSIS OF HUMAN CYSTICERCOSIS
}

By

\author{
SHIMAA A. ABDEL-RADI ${ }^{1}$, YOSRA N. ABD EL-HAFEZ ${ }^{2}$ AND AYMAN T. MORSY ${ }^{3^{\text {t* }}}$ \\ Departments of Parasitology, Faculty of Veterinary Medicine ${ }^{1}$, Cairo University, Giza, \\ Faculty of Medicine, FayoumUniversity ${ }^{2}$, El-Fayoum, and Consultant Tropical \\ Medicine and $\mathrm{Fever}^{3}$, Ministry of the Interior, Egypt \\ ( ${ }^{*}$ Correspondence:Shimaa.abdelradi@cu.edu.eg, ayman.tosson@med.asu.edu.eg)
}

\section{Abstract}

Human cysticercosis is a serious disease caused by Cysticercus cellulose (C.c.); the larval stage of Taenia solium. The disease affects pigs and pork meat consuming people. Cysticercosis was diagnosed in pigs during post-mortum (P.M.) inspection while specific serologic one must be used for human diagnosis of cysticercosis. The present study evaluated the diagnostic sensitivity and specificity of three antigens, extracted from living non-calcified C.c. larvae from naturally infected pig muscles, in diagnosis of infection by cysticercosis in human and pigs by using ELISA. The results showed that C.c. fluid Ag (C.c. Fl) proved to be the most sensitive one followed by C.c. scolices Ag (C.c. Scol)and then C.c. wall $\mathrm{Ag}($ C.c. Wl), with sensitivities of $85.55 \%, 74.44 \%$ \& $67.77 \%$, respectively. C.c. Fl-Ag gave the high sensitivity (73.33\%) in diagnosis cysticercosis infection in suspected patients with perfect classification for Kapp agreement. Moreover, C.c. Fl-Ag showed high median ELISA optical density (OD) value, but without significant difference $(P \geq 0.05)$ for OD values in diagnosis of infection in human or pig sera. Also, C.c. Fl-Ag gave the highest specificity $92.5 \%$, in excluding cross reaction versus other human hepatic diseases as schistosomiasis mansoni, Hepatitis $\mathrm{C}$ virus and hydatidosis as well as trichinosis spiralis Abs in infected pigs. The C.c.Fl-Ag contained the highest number (13) of specific immunogenic fractions by using EITB, which fractioned at the MW of 140, 135, 130, 105, 100, 95, 68, 58, 45, 35, 28, $25 \& 22 \mathrm{kDa}$. But, the fractionated C.c. Wl-Ag contained ten immunogenic fractions at MW of 100, 75, $68,63,58,45,42,35,25 \& 18 \mathrm{kDa}$, and the C.c. Scol-Ag contained nine fractions at MW of 135, 100, $68,66,63,58,45,42 \& 35 \mathrm{kDa}$. Consequently, suitability of C.c.Fl-Ag antigen could be used for epidemiological study of zoonotic cysticercosis by using ELISA.

Keywords: Cysticercosis, human, pig, Antigen fraction, EITB, ELISA.

\section{Introduction}

Zoonotic taeniasis is a parasitic disease caused by ingestion of under cooked Cysticercus bovis of $T$. saginata in beef or $C$. cellulose of $T$. solium in pork or $T$. asiatica in pork liver (WHO, 2020). Human infection was also acquired via the fecal-oral route, or by ingesting contaminated food or water (Gonzales et al, 2016). In T. solium the autoinfected eggs causing human cysticercosis in his tissue, and thus he acts as intermediate and definitive hosts (Bouteille, 2014). Thus, C. cellulose established in the CNS (neurocysticercosis), or muscles, skin, eyes, and other tissues causing chronic headache, blindness, convulsions, and epileptic seizures, and even fatal (Symeonidouet al, 2018), also hydrocephalus, meningitis, dementia, and CNS lesions was reported (Trevisan et al, 2018).

Taeniasis is usually characterized by mild or non-specific symptoms, as abdominal pain, nausea, diarrhea or constipation (Ito et al, 2003). In endemic countries, human cysticercosis is associated with various signs and symptoms depended on its number, size, stage, site, and pathological changes.

Undoubtedly, taeniasis could be easily diagnosed by eggs in stool or gravid segments on buttocks. Human cysticercosis was more difficult to diagnose with absence of specific clinical manifestations that went with other human diseases with diagnostically challenging fashions (Del Brutto, 2014).

Several serological tests were performed to detect and confirmation human cysticercosis (Winkler, 2012). Sero-diagnosis detecting specific parasite antibodies gave more accuracy and overcame some disadvantages of traditional carpological diagnostic techniques. ELISA proved to be one of the commonest, easily applicable tests, which accura- 
cy depended on the character and stability of the used antigen as compared with others such as western-blot (Zhang et al, 2012).

Generally, Saratsis et al. (2019) reported that in the Middle East and North African countries Taenia species health burden was low, but the economic burden was large, due to condemnation of infected carcasses and carcass parts. In Egypt, Haridy et al. (1999) in Cairo reported Taenia saginata, T. solium and cysticercosis in slaughtered cattle, buffaloes, sheep and pigs. Abdel-Hafeez et al. (2015) in El-Minia City among 100 cattle, 100 goats, and 100 pigs slaughtered in ElMinia Governmental Slaughterhouses found Cysticercus bovis in 20\% of cattle and C. cellulosae in $12 \%$ of pigs.

The present study aimed to find out a cheap specific antigen to diagnose cysticercosis cellulosae in live pigs, and workers in pig slaughterhouses, and farms. So, to verify this aim three crude antigens were prepared from live non-calcified $C$. cellulosae extracted from natural infected pigs, and their diagnostic sensitivity and specificity were evaluated versus naturally infected and suspected human and pig sera by using ELISA. Besides, the different immunogenic fractions in each antigen were evaluated using the Western-blot assay as a standard diagnosis.

\section{Materials and Methods}

Ethical approval: The method of sera collection was approved by the institutional review board of the Institutional Animal Care \& Use Ethical Committee (CU-IACUC), Cairo University. The work was done from January to August 2020.

Samples collection: C. cellulosae, sera and stools were collected from pigs and pig breeders and consumers at Al-Mokatum District, Cairo. The C. cellulosae were extracted from the heart muscles of freshly slaughtered pigs at post-Mortem inspection. The samples were put in separate labeled plastic bags and transported in ice box to the experimental laboratory, Department of Parasitology, Cairo Faculty of Veterinary Medicine.

Cysticercal antigens: The collected sound live non-calcified cysticerci cellulosae were washed in phosphate-buffered saline (PBS). Three antigens were prepared from each cyst, fluid-Ag (C.c. Fl), scolex-Ag (C.c. Scol) and wall-Ag (C.c.W1). The larvae were individually ruptured in Petri-dishes using scalpels and needles, the released fluid was collected for centrifugation (Mahdyet al, 2017). Scolices and membranes were dissected out, washed in PBS to prepare the crude antigens (Arrudal et al, 2005), the protein content of each was determined (Bradford, 1976), and then stored at $-20^{\circ} \mathrm{C}$ until needed.

Human \& animal sera: Sera of breeders or taeniasis pigs as proved by stools examination for 3 successive days using fluke finder technique (Welch et al, 1987) for large sized eggs and concentration flotation technique (Soulsby, 1982) for small sized ones, and protozoa. Diaphragm pieces were trichinoscopy examined to exclude trichinosis (Taher et al, 2017).

Antigenic sensitivity: Thirty blood sera were collected from positive stool of breeders and pork consumers at Al-Mokatum District. Also, 30 sera and live non-calcified $C$. cellulosae were collected from slaughtered pigs. Twenty sera were collected from crossmatched healthy not pork consumers volunteers, and 20 sera from newly born suckling pigs parasite-free as negative human and pig controls.

Antigenic specificity: Thirty sera were collected from pig breeders with history of clinical manifestations suggestive taeniasis/cysticercosis, with negative stool for taeniasis. Also, ten human sera were taken from patients each of active schistosomiasis mansoni, Hepatitis CV \& hydatidosis and from trichinosis infected pigs.

Indirect ELISA (Minozzo et al, 2008): The tests and reference values of the positive and negative sera were optimized after checkerboard titration (Sigma, USA). All reagents were used as $100 \mu 1 /$ well, tested sera were diluted with PBS as 1:100, and Horseradish peroxidase-conjugated anti-human \&/or anti-pig IgG was diluted as 1:2000. Diagnost- 
ic color was determined by adding the substrate (O-phenylene diamine dihydrochloride or OPD), and absorbance (OD) values were measured at $450 \mathrm{~nm}$ with an automated Titerteckmultiskan ELISA reader. Antigen cutoff value was individually determined versus tested sera. The cut-off as mean value of negative control (Lardeux et al, 2016) was $0.12666,0.4532 \& 0.4226$ (OD) for positive sera versus C.c. Fl-Ag, C.c. Scol-Ag \& C.c. Wl-Ag, respectively.

Antigens fractionation and proteins transferring: Antigens were fractionated by using SDS-PAGE analysis under reduced conditions using $12 \%$ non-gradient slab gel \& 5\% stacking gel (Laemmli, 1970). The fractions were calibrated versus molecular weight markers (Mr) (Sigma SDS-100B) and fractionated proteins were transferred at $10 \mathrm{~V}$, $100 \mathrm{~mA}$ overnight at $4^{\circ} \mathrm{C}$, from gel onto nitrocellulose membrane (NC), the $\mathrm{NC}$ sheet was dried in room temperature and stored in freezing temperature until needed.

Western-blot assay (EITB) determination of specific protein fractions: Longitudinal NC strips $(100 \times 4.0 \mathrm{~mm})$ contained different fractionated antigens were cut. Each strip antigen was reacted separately versus $T$. solium infected and control human and pig sera at $1: 100$ dilution, $3.0 \mathrm{ml}$ of sera/ strip for $2 \mathrm{hr}$ using EITB (Towbin et al, 1979). After washing, strips were incubated in 1:1000 Horseradish peroxidase-conjugated antihuman or anti-pig IgG (Sigma, USA) in blocked buffer. Substrate (4-chloro-1-naphthol, Sigma) was added to reveal the IgG/antigen reaction. Protein fractions that reacted specifically versus infected serum samples and did not react versus control negative samples were considered the specific protein fractions.

Statistical analysis: Data were tabulated and analyzed (SPSS version 26 software, Chicago, IL, USA) by using Chi-square $\left(\chi^{2}\right)$ and Kappa agreement tests scale (Landis and Koch, 1977). A statistical comparison between the median values was done by independent sample Kruskal-Wallis test and significance values were adjusted by the Bon- ferroni correction for multiple tests. Values of $p \leq 0.05$ were considered significant.

\section{Results}

The sensitivity value the three tested antigens in detecting Cysticercus cellulose antibodies in taeniasis patients and pigs by indirect ELISA showed that the C.c. Fl-Ag was the most sensitive followed by C.c. Scol-Ag and C.c. Wl-Ag. Sensitivity was $85.55 \%$, $74.44 \%$ \& $67.77 \%$ respectively that which antigenic sensitivity was high versus infected pig sera and then versus infected patients sera. The C.c. Fl-Ag gave high sensitivity $(73.33 \%)$ in diagnosing suspected patients on pork meat without eggs in stools. The high diagnostic significance for C.c. Fl-Ag with perfect Kapp agreement was $(\mathrm{P} \leq 0.05)$ as compared to other antigens in diagnosing infection in human and pig sera.

The C.c. Fl-Ag proved to high sensitivity concerning the Median ELISA OD value without significant difference $(\mathrm{P} \leq 0.05)$ in Median ELISA OD value in diagnosis antiC.c. Abs in sera of infected human or pigs using C.c. Fl-Age. But, this difference was significant by using C.c. Scol-Ag \& C.c.WlAg.

As to specificity, the three C.c. antigens did not cross react with antibodies in infected tested sera. The C.c.Fl-Ag gave average specificity $92.5 \%$ compared to $80 \%$ other two antigens. C.c.Fl-Ag gave absolute specificity $(100 \%)$ as did not cross react with $S$. mansoni and/or HCV infected patients antibodies, specificity decreased to $90 \%$ versus hydatidosis infected patients and to $80 \%$ versus trichinosis infected pigs.

Difference in sensitivity and specificity of the three prepared C.c. antigens; The amount of immunogenic protein fractions of each C.c. antigen were investigated after fractionation and treating fractionated antigens in each case versus five pig sera selected with low and high number of C.c. in heart muscles as well as five negative sera. The C.c. Fl-Ag contained the highest number of immunogenic fractions (13) protein fractions. They ranged from $135 \mathrm{kDa}$ to $22 \mathrm{kDa}$ corre- 
sponded to molecular weights (MW) of 140, 135, 130, 105, 100, 95, 68, 58, 45, 35, 28, 25 \& $22 \mathrm{kDa}$, but fractionated C.c. Wl-Ag showed only ten immunogenic fractions at MW of 100, 75, 68 (broad bands), 63, 58, $45,42,35,25 \& 18 \mathrm{kDa}$. The lowest one (9) recorded in C.c.Scol-Ag corresponded to MW of 135, 100, 68, 66, 63, 58, 45, 42 \& 35 $\mathrm{kDa}$. Fractions at $\mathrm{MW} 100 \mathrm{kDa}, 68 \mathrm{kDa}$,
$58 \mathrm{kDa}, 45 \mathrm{kDa} \& 35 \mathrm{kDa}$ were the commonest protein fractions among the three C.c. antigens. Also, fraction corresponded to MW at $135 \mathrm{kDa}$ was commonest among C.c. Fl-Ag \& C.c. Scol-Ag. The fractions corresponded to MW at $63 \mathrm{kDa} \& 25 \mathrm{kDa}$ were the commonest among C.c. Fl-Ag \&C.c. W1Ag. The details were given in tables $(1,2,3$ \& 4) and figure (1).

Table 1: ELISA -sensitivity of C. cellulose (C. c.) antigens in capturing of anti-Cysticercus antibodies in patients and pigs.

\begin{tabular}{|c|c|c|c|c|}
\hline \multirow{2}{*}{ Tested serum Samples } & \multicolumn{3}{c|}{ Number \& \% of positive and negative sera versus C. cellulose } \\
\cline { 3 - 5 } & Fl-Ag & Scol-Ag & Wl-Ag \\
\hline \multirow{2}{*}{ T. solium infected human $(\mathrm{n}=30)$} & Positive & $27(90 \%)$ & $23(76.66 \%)$ & $20(66.6 \%)$ \\
\cline { 2 - 4 } & Negative & $3(10 \%)$ & $7(23.33 \%)$ & $10(33.3 \%)$ \\
\hline \multirow{2}{*}{ C.c. infected pig $(\mathrm{n}=30)$} & Positive & $28(93.33 \%)$ & $25(83.33 \%)$ & $26(86.66 \%)$ \\
\cline { 2 - 5 } & Negative & $2(6.66 \%)$ & $5(16.66 \%)$ & $4(13.33 \%)$ \\
\hline Suspected C.c. infected patients $(\mathrm{n}=30)$ & Positive & $22(73.33 \%)$ & $20(66.66 \%)$ & $17(56.66 \%)$ \\
\cline { 2 - 5 } & Negative & $8(26.66)$ & $10(33.33 \%)$ & $13(43.33 \%)$ \\
\hline Mean sensitivity & & $85.55 \%$ & $74.44 \%$ & $67.77 \%$ \\
\hline
\end{tabular}

Table 2: Analysis of different C. cellulose (C. c.) antigens in detection of anti- C. cellulose-Abs in patients and pigs.

\begin{tabular}{|c|c|c|c|c|c|}
\hline Samples & Gold standard & Reaction Versus & Pearson Chi square $\left(\chi^{2}\right)$ & Kappa value & $P$ value \\
\hline \multirow{3}{*}{ T. solium patients $(\mathrm{n}=30)$} & \multirow{2}{*}{$\begin{array}{c}\text { Taenia } \text { eggs } \\
\text { in stool }\end{array}$} & C.c. $\mathrm{Fl}-\mathrm{Ag}$ & $2 . .111$ & 0.835 & 0.006 \\
\cline { 3 - 6 } & & C.c. Scol Ag & 1.846 & 0.657 & 0.025 \\
\cline { 3 - 6 } & & C.c. Wl-Ag & 1.432 & 0.635 & 0.044 \\
\hline \multirow{2}{*}{$\begin{array}{c}\text { C. cellulose infected pig } \\
(\mathrm{n}=30)\end{array}$} & \multirow{2}{*}{$\begin{array}{c}\text { C. cellulose } \\
\text { in muscles }\end{array}$} & C.c. $\mathrm{Fl}-\mathrm{Ag}$ & 2.222 & 0.885 & 0.003 \\
\cline { 3 - 7 } & & C.c. Scol Ag & 1.988. & 0.660 & 0.105 \\
\cline { 3 - 6 } & C.c. Wl-Ag & 1.645 & 0.703 & 0.008 \\
\hline
\end{tabular}

Table 3: Median ELISA OD values by different C. cellulose antigens in diagnosing anti-C.c. IgG-Abs in patients and pigs

\begin{tabular}{|c|c|c|c|}
\hline \multirow{2}{*}{ Tested sera } & \multicolumn{3}{|c|}{ Median ELISA OD value using C. cellulose } \\
\cline { 2 - 4 } & Fl-Ag & Scol-Ag & Wl-Ag \\
\hline T. solium patients $(\mathrm{n}=30)$ & $0.7710^{\mathrm{Aa}} \pm 0.08$ & $0.5936^{\mathrm{Bab}} \pm 0.02$ & $0.5065^{\mathrm{Bab}} \pm 0.13$ \\
\hline C. cellulose infected pig $(\mathrm{n}=30)$ & $0.8301^{\mathrm{Aa}} \pm 0.07$ & $0.6980^{\mathrm{Bb}} \pm 0.02$ & $0.6580^{\mathrm{Ca}} \pm 0.03$ \\
\hline Suspected C. cellulose infected patients $(\mathrm{n}=30)$ & $0.6705^{\mathrm{Ab}} \pm 0.40$ & $0.5765^{\mathrm{Ab}} \pm 0.41$ & $0.4965^{\mathrm{Bb}} \pm 0.21$ \\
\hline
\end{tabular}

Data represented as median \pm IQR (interquartile rang). Values with different small letters $=$ significantly different, those in Row with different capital letters $=$ significant different $(\mathrm{P} \leq 0.05)$

Table 4: ELISA-specificity of different C. cellulose antigens in capturing of anti-Cysticercus antibodies with other parasites.

\begin{tabular}{|l|c|c|c|}
\hline \multirow{2}{*}{ Tested serum Samples } & \multicolumn{3}{|c|}{ Positive sera and specificity versus C. cellulose } \\
\cline { 2 - 4 } & Fl-Ag & Scol-Ag & Wl-Ag \\
\hline Schistosomiasis mansoni patients $(\mathrm{n}=10)$ & $0.0(100 \%)$ & $2.0(80 \%)$ & $2.0(80 \%)$ \\
\hline Hepatitis CV patients $(\mathrm{n}=10)$ & $0.0(100 \%)$ & $1.0(90 \%)$ & $1.0(90 \%)$ \\
\hline Hydatidosis granulosus patients $(\mathrm{n}=10)$ & $1.0(90 \%)$ & $2.0(80 \%)$ & $2.0(80 \%)$ \\
\hline Trichinosis spiralis infected pigs $(\mathrm{n}=10)$ & $2.0(80 \%)$ & $3.0(70 \%)$ & $3.0(70 \%)$ \\
\hline Mean specificity & $3.0(92.5 \%)$ & $8.0(80 \%)$ & $8.0(80 \%)$ \\
\hline Healthy human control $(\mathrm{n}=10)$ & $0.0(100 \%)$ & $0.0(100 \%)$ & $0.0(100 \%)$ \\
\hline Newly borne pigs $(\mathrm{n}=10)$ & $0.0(100 \%)$ & $0.0(100 \%)$ & $0.0(100 \%)$ \\
\hline
\end{tabular}

\section{Discussion}

Zoonotic cysticercosis confused with some Egyptian human hepatic disorders as schistosomiasis mansoni (Haggag et al, 2017), HCV (Helal et al, 2018) hydatidosis (Ibrahim and Morsy, 2020), and trichinosis in man and pig (Younis et al, 2005).

In the present study, ELISA sensitivities of the three C.c. antigenic extracts in capturing of anti-C.c. Abs in sera of infected hum-an and pigs showed that C.c. Fl-Ag was the most sensitive one followed by C.c. Scol-Ag and then C.c. Wl-Ag. This agreed with Arruda et al. (2005) who found the C.c. antigenic sensitivity was high versus infected pig sera and then infected patient sera.

In the present study, C.c. Fl-Ag gave high specificity (92.5\%) for exclusion of cross reacted Abs present in human and pig sera infected by other parasites; S. mansoni, HCV, 
and hydatidosis patients as well as trichinosis pigs. The two $C$. $c$. antigens ones gave $80 \%$. This agreed with Sabry and Waheed (2007) who reported that antigens extracted from cyst fluid were ELISA highly specific and sensitive in diagnosis.

In the present study, EITB evaluated the three C.c. antigenic specific fractionations. The three C.c. antigens versus infected and control pig sera showed that C.c. Fl-Ag contained 13, the highest immunogenic fractions corresponded to MW of $140,135,130$, $105,100,95,68,58,45,35,28,25 \& 22$ $\mathrm{kDa}$, followed by C.c. Wl-Ag that contained ten immunogenic fractions at MW of 100 , 75, 68 (broad bands), 63, 58, 45, 42, 35, 25 \& $18 \mathrm{kDa}$, but lowest one was nine in C.c. Scol-Ag corresponded to MW at to MW of $135,100,68,66,63,58,45,42 \& 35 \mathrm{kDa}$ with several common fractions among between. This agreed with Pallampale et al. (2019) who analyzed SDS-PAGE of whole cyst antigen (WCA) and C.c. scolex antigen (SA) detected that SA fractions ranged from $12 \mathrm{kDa}$ to $98 \mathrm{kDa}$, and gave good specificity (98.35\%) sensitivity and $98.58 \%$. Neto et al. (2007) reported that 21 bands of C.c. scolex antigen ranged from $15 \mathrm{kDa}$ to $200 \mathrm{kDa}$, the majority of them corresponded to ELISA efficacy. Also, Zimic et al. (2009) found that cystic fluid contained 53 fractions \& $25 \mathrm{kDa}$ by ELISA showed high sensitivity and specificity in human cysticercosis diagnosis.

In the present study, the C.c. Fl-Age with the highest immunogenic fractions gave the best specificity and sensitivity with high median ELISA OD values in positive sera as compared to the other two antigens. This agreed with Neto et al. (2007) and Taher et al. (2017) who found a direct relation between antigen diagnostic efficacy and its specific immunogenic protein fractions.

\section{Conclusion}

The present study showed that the C.c. Fl$\mathrm{Ag}$ is a low cost and easily prepared ELISA antigen with high sensitivity and specificity as well as high specific immunogenic polypeptide protein fractions. Thus, it was reco- mmended in epidemiological study of cysticercosis in man and pig.

\section{References}

Abdel-Hafeez, EH, Kamal, AM, Abdelgelil, N H, Abdel-Fatah, M, 2015: Parasites transmitted to human by ingestion of different types of meat, El-Minia City, El-Minia Governorate, Egypt. J. Egypt. Soc. Parasitol. 45, 3:671-80

Arruda, GC, da Silva, AD, Quagliato, EM, Maretti, MA, Rossi, CL, 2005: Evaluation of Taenia solium and Taenia crassiceps cysticercal antigens for the serodiagnosis of neurocysticercosis. Trop. Med. Inter. Hlth. 10, 10:1005-12.

Bouteille, B, 2014: Epidemiology of cysticercosis and neurocysticercosis Med. Sante Trop. 24, 4:367-74

Bradford, MM, 1976: A rapid and sensitive method for the quantification of microgram quantities of protein utilizing the principle of protein-dye binding. Anal. Biochem. 72:248-54.

Del Brutto, OH, 2014: Neurocysticercosis. In: Handbook of Clinical Neurology. doi: 10.1016/ B978-0-7020-4088-7.00097-3.

Gonzales, I, Rivera, JT, Garcia, HH, 2016: Pathogenesis of Taenia solium taeniasis and cysticercosis in Peru. Parasit. Immunol. 38, 3:13646.

Haggag, AA, Rabiee, A, Abd Elaziz, KM, Gabrielli, AF, Abdel Hay, R, et al, 2017: Mapping of Schistosoma mansoni in the Nile Delta, Egypt: Assessment of the prevalence by the circulating cathodic antigen urine assay. Acta Trop. 167:9-17.

Haridy, FM, Ibrahim, BB, Morsy, TA, Ramadan, NI, 1999: Human taenaisis and cysticercosis in slaughtered cattle, buffaloes and pigs in Egypt. J. Egypt. Soc. Parasitol. 29, 2:375-94.

Helal, HEB, Yuonis, A, Shaker, RHM, Elawady, MA, 2018: Prevalence of HCV infection in household contacts of chronic liver diseases cases in Egypt. J. Environ. Publ. Hlth. Oct 24; 2018:2153537.

Ibrahim, EA, Morsy, TA, 2020: Tissue sparing technique in liver hydatid diseases: Three-way technique versus hydatid cone technique. J. Egypt. Soc. Parasitol. 50:378-89.

Ito, A, Nakao, M, Wandra, T, 2003: Human taeniasis and cysticercosis in Asia. Lancet 362, 9399:1918-20.

Laemmli, UK, 1970: Cleavage of structural proteins during the assembly of the head of bacteriophage T4. Nature 227:680-5. 
Landis, J, Koch, G, 1977: The measurement of observer agreement for categorical data. Biometrics 33:159-74.

Lardeux, F, Torrico, G, Aliaga, C, 2016: Calculation of the ELISA's cut-off based on the change-po-int analysis method for detection of Trypanosoma cruzi infection in Bolivian dogs in the absence of controls. Mem. Inst. Oswaldo Cruz 111, 8:501-4.

Mahdy, OA, Mousa, WM, Abdel-Maogood, S Z, Abdel-Radi, S, El-Bahy, MM, 2017: Characterization of immunogenic protein fractions of sheep cysticercosis in Cairo, Egypt. J. Hellenic Vet. Med. Soc. 68, 3:291-8.

Minozzo, JC, De Moura, J, Almeida, SM, Thomaz-Soccol, V, 2008: Crude antigen from Taenia crassiceps cysticercus used as heterologous antigen in ELISA and in EITB for neurocysticercosis diagnosis of patients from Paraná-Brazil Braz. Arch. Biol. Technol. 51, 6:1127-37.

Neto, FI, Pianetti-Filho, G, Araújo, RN, Nascimento, E, 2007: Immunodiagnosis of human neuro-cysticercosis by using semipurified scolex antigens from Taenia solium cysticerci. Rev. Soc. Bras. Med. Trop. 40, 2:163-9.

Sabry, MA, Reda, WW, 2008: Infection by cyst producing protozoa among human and food producing animals in Egypt. J. Biol. Sci. 8, 5: 889-95.

Saratsis, A, Sotiraki, S, Braae, UC, Devleesschauwer, B, Dermauw, V, 2019: Epidemiology of Taenia saginata taeniosis/cysticercosis: A systematic review of the distribution in the Middle East and North Africa Parasit. Vectors 12, 1: 113. doi: 10.1186/s13071-019-3339-5.

Soulsby, EJ, 1982: Helminthes, Arthropods and Protozoa of Domesticated Animals (Textbook):

$6^{\text {th }}$ Edition, Bailliere Tindall \& Cassell, London. Symeonidou, I, Arsenopoulos, K, Tzilves, D, Soba, B, Sarah Gabriël, S, et al, 2018: Human taeniasis/cysticercosis: a potentially emerging parasitic disease in Europe. Ann. Gastroenterol. 31, 4:406-12.

Taher, EE, Meabed, EM, El Akkad, DH, Kamel, NO, Sabry, MA, 2017: Modified dotELISA for diagnosis of human trichinellosis. Exp. Parasitol. 177:40-6

Towbin, H, Stachelin, T, Gordon, J, 1979: Elecrophoretic transfer of proteins from polyacrylamide gels to nitrocellulose sheets: Procedures and some applications. Proc. Nat. Acad. Sci. 76: 4350-4; USA.

Trevisan, C, Sotiraki, S, Laranjo-González, M, Dermauw, V, Wang, Z, et al, 2018: Epidemiology of taeniosis/cysticercosis in Europe, a systematic review: Eastern Europe. Parasit. Vectors 11, 1:569. doi: 10.1186/s13071-018-3153-5. Welch, S, Malone, J, Geaghan, H, 1987: Herd evaluation of Fasciola hepatica in Louisiana cattle by an ELISA. Am. J. Vet. Res. 48: 345-7.

WHO, 2020: Taeniasis/cysticercosis, Wld. Hlth. Organ., Geneva, Switzerland

Winkler, AS, 2012: Neurocysticercosis in subSaharan Africa: A review of prevalence, clinical characteristics, diagnosis, and management. $\mathrm{Pa}-$ thol. Glob. Hlth. 106:261-74.

Younis, AI, Bassiouny, S, Abdel Aziz, J, Khalafallah, O, 2005: Intercellular adhesion molecule-2 (ICAM-2) in experimental trichinosis. J. Egypt. Soc. Parasitol. 35, 3:1019-26.

Zhang, W, Wen, H, Li, J, Lin, R, McManus, DP, 2012: Immunology and immunodiagnosis of cystic echinococcosis: an update. Clin. Dev. Immunol. 2012: 101895. online 2011 Dec 25.

Zimic, MJ, Pajuelo, M, Rueda, D, López, C, Arana, Y, et al, 2009: Utility of a protein fraction with cathepsin-L like activity purified from Cysticercus fluid of Taenia solium in diagnosis of human cysticercosis. Am. J. Trop. Med. Hyg. 80:964-70.

\section{Explanation of figure}

Fig. 1: Reacted polypeptides in fractionated $C$. cellulose antigens on NC strips versus infected pig sera (Lane 1,3 \& 5), and negative pig sera (Lane 2, 4 \& 6) using EITB, MWSt. = Molecular weight protein slandered (Sigma)

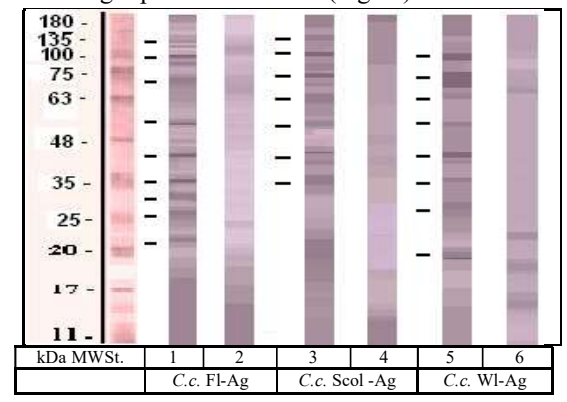

